\title{
Laparoscopic Revision of Vertical Banded Gastroplasty to Sleeve Gastrectomy for Gastric Outlet Obstruction: Early Experience in Cohort of 18 Patients
}

Keywords: Gastric outlet obstruction; Revisional bariatric surgery: Laparoscopic sleeve gastrectomy; Vertical banded gastroplasty

\begin{abstract}
Introduction: The long-term effectiveness of Vertical Banded Gastroplasty (VBG) is limited due to development of complications related to gastric outlet obstruction at the band site. Surgical reversal or conversion to Roux-en-Y gastric bypass has been the mainstay of treatment for complications. The purpose of this study was to assess outcomes of revising VBG to laparoscopic sleeve gastrectomy (LSG) in patients presenting with gastric outlet obstruction.

Methods: We retrospectively reviewed 18 consecutive patient that underwent revision of VBG to LSG for gastric outlet obstruction, from 2008 to 2012, in an academic institution.

Results: The mean age of the patients was $47 \pm 11$ years $189 \%$ females), with mean preoperative BMl of $36 \pm 8 \mathrm{~kg} / \mathrm{m} 2$. The mean length of time from the original VBG was $10 \pm 7$ years. Gastric outlet obstruction, diagnosed by EGD and UGI, was present in $100 \%(n=18)$. Intolerance to solid food was present in $39 \%$, while $44 \%$ had reflux symptoms. The mean operative time was $187 \pm 50 \mathrm{~min}$. There was one conversion to open sleeve gastrectomy secondary to dense adhesions. There were two staple-line leaks $(11 \%)$ requiring reoperation. There were no perioperative bleeds and no deaths. Symptom resolution was observed in $95 \%$ of patients. Postoperative BMI was $33 \pm 6 \mathrm{~kg} / \mathrm{m} 2$ at 15-month follow-up.

Conclusion: Revision of VBG to LSG is a safe and feasible option for patients presenting with gastric outlet obstruction with low BMI. This procedure alleviates gastric outlet obstruction, while maintaining gastric restriction.
\end{abstract}

\section{Introduction}

Vertical Banded Gastroplasty (VBG) was the most commonly performed primary bariatric surgery in the late 1980s. Avoiding the potentially devastating metabolic side-effects of the malabsorptive procedures at the time and due to its relative simplicity, it gained popularity as a primarily restrictive procedure [1]. While having initially promising short-term results, high long-term failure rates in the range of $20-79 \%$ made the VBG less appealing [2,3]. These high failure rates were usually the result of either weight recidivism or other long-term complications including gastric outlet stenosis, staple line disruption, incisional hernia, band erosion and severe esophagitis [4-6]

\section{Journal of}

Obesity and

Bariatrics

\section{Noah J. Switzer ${ }^{*}$, Richdeep S. Gill ${ }^{2}$, Xinzhe $\mathrm{Shi}^{3}$, John A. Primomo ${ }^{4}$, Lee Morris ${ }^{4}$, Shazheer Karmali $^{1,3}$ and Vadim Sherman ${ }^{4}$}

${ }^{I}$ Department of Surgery, University of Alberta, Edmonton, Alberta, Canada

${ }^{2}$ Department of Surgery, University of Calgary, Calgary, Alberta, Canada

${ }^{3}$ Center for the Advancement of Minimally Invasive Surgery (CAMIS), Royal Alexandria Hospital, Edmonton, Alberta, Canada ${ }^{4}$ The Methodist Hospital, Houston, Texas, USA

\section{*Address for Correspondence}

Noah J. Switzer, Department of Surgery, 2D, Walter C Mackenzie Health Sciences Centre, 840-112 Street, University of Alberta, T6G 2B7, Edmonton, Alberta, Canada, Tel: (780) 884-2964; Fax: (780) 407-7394; E-mail: nswitzer@ualberta.ca

Submission: 24 October, 2016

Accepted: 26 November, 2016

Published: : 03 December, 2016

Copyright: (๑) 2016 Switzer NJ, et al. This is an open access article distributed under the Creative Commons Attribution License, which permits unrestricted use, distribution, and reproduction in any medium, provided the original work is properly cited.

Outlet stenosis at the neo-pylorus junction is amorbid complication following VBG, reported in approximately $10-20 \%$ of patients, leading to clinical manifestations of gastric outlet obstruction $[3,7,8]$. Usually a late complication, with an interval of about 5 years following the original surgery, patients can become quite symptomatic complaining of intractable vomiting, dysphagia or reflux [3,9]. Band slippage, occurring in $1-20 \%$ of patients, is another recognized etiology of gastric outlet obstruction [10]. As a general consequence of this obstruction, patients develop maladaptive eating strategies leading to significant weight re-gain [3].

Revisional bariatric surgery from the VBG to another bariatric procedure is becoming increasingly common, with the literature quoting rates between $10-65 \%$ [3,11,12]. Surgical reversal or conversion to Roux-en-Y gastric bypass (RYGB) has been the mainstay of treatment for complications. Due to its relative infancy, the Laparoscopic Sleeve Gastrectomy (LSG) is only starting to be used as a revisional option for failure. Initial studies have been shown it to be a feasible option with excess weight loss ranging between 16-64\% $[2,13,14]$. The purpose of this study was to assess outcomes of revising VBG to laparoscopic sleeve gastrectomy (LSG) in patients presenting with gastric outlet obstruction.

\section{Methods}

\section{Study design}

Retrospective review of data collected regarding VBG patients presenting with gastric outlet obstruction, and undergone revision to LSG conducted by single surgeon at our institution from January 2008 and December 2010. The institutions ethics board granted approval for the study.

\section{Data recorded}


Citation: Switzer NJ, Gill RS, Shi X, Primomo JA, Morris L. Laparoscopic Revision of Vertical Banded Gastroplasty to Sleeve Gastrectomy for Gastric Outlet Obstruction: Early Experience in Cohort of 18 Patients. J Obes Bariatrics. 2016;3(1): 4.

Preoperative characteristics collected were patient's age, sex, initial weight and BMI. Preoperative symptoms were also collected. Selective use of upper contrast gastro graffin was utilized. Confirmation of gastric outlet obstruction was made with upper endoscopy. The length of hospital stay and complication rate was also recorded.

\section{Outcomes}

The outcomes recorded were mean time from initial VBG, mean absolute weight loss, and mean change in BMI, and improvement in obstructive symptoms.

\section{Surgical technique}

Patients were positioned in the supine position and received deep vein thrombosis prophylaxis. Eroded gastric mesh was removed endoscopically, which intact mesh was removed laparoscopically during the operation. A gastrotomy was made distally on the stomach, and a Covidien" Tri-staple device was inserted through the stoma and fundus, and used to remove restriction at the narrowed stoma. The greater curvature vessels were divided using a harmonic scalpel. The sleeve gastrectomy was constructed over a 50 French sizing bougie inserted orally. The antral staple line was initiated with $2 \times 60$ mm black firings of the Covidien" Tri-stapler, followed by $4-5 \mathrm{x}$ $60 \mathrm{~mm}$ purple firings. The staple line was started $6 \mathrm{~cm}$ proximal to the pylorus. The specimen was retrieved. Contrast study was preformed on post operative day 1 . The patients were discharged home when tolerating liquid diet.

\section{Statistical analysis}

Descriptive summaries of age, gender, BMI, OR time, length of stay, complications, and follow-up time were conducted for this series of patients. Mean \pm SD or percentage used were appropriate.

\section{Results}

18 patients were included in this study. The mean age of the patients was $47 \pm 11$ years ( $89 \%$ females), with mean preoperative BMI of $36 \pm 8 \mathrm{~kg} / \mathrm{m}^{2}$ (Table 1). The mean length of time from the original VBG was $10 \pm 7$ years. Gastric outlet obstruction, diagnosed by EGD and UGI, was present in $100 \%(\mathrm{n}=18)$. Intolerance to solid food was present in $39 \%$, while $44 \%$ had reflux symptoms. The mean operative time was $187 \pm 50 \mathrm{~min}$. There was one conversion to open

Table 1: Basic demographics of gastric outlet obstruction patients revised to sleeve gastrectomy.

\begin{tabular}{|c|c|}
\hline Variables & \\
\hline Patients (n) & 18 \\
Female (\%) & 89 \\
Male (\%) & 11 \\
\hline Age (year) & \\
Mean \pm SD & $47.2 \pm 10.8$ \\
\hline Pre-operative BMI (kg/m $\left.{ }^{2}\right)$ & $36 \pm 8$ \\
\hline Mean \pm SD & $10 \pm 7$ \\
\hline Time elapse from original VBG (year) & \\
Mean \pm SD & 44 \\
\hline Symptoms & 39 \\
\hline Heartburn/reflux (\%) & \\
Intolerance to Solids (\%) & \\
\hline
\end{tabular}

Table 2: Perioperative results of gastric outlet obstruction patients revised to sleeve gastrectomy.

\begin{tabular}{|c|c|}
\hline Variables & \\
\hline Operating Time (min) & $187 \pm 50$ \\
\hline Length of Stay (days) & $3.86 \pm 3.8$ \\
\hline 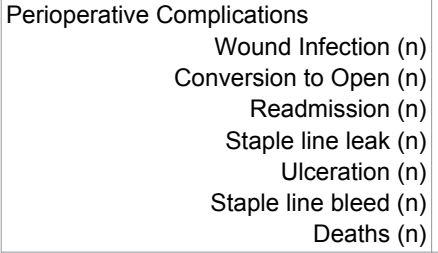 & $\begin{array}{l}1 \\
1 \\
5 \\
2 \\
1 \\
0 \\
0\end{array}$ \\
\hline Follow up time (months) & $14.7 \pm 14.4$ \\
\hline $\begin{array}{l}\text { Follow up at } 3 \text { months } \\
\qquad \begin{array}{r}\text { BMI }\left(\mathrm{kg} / \mathrm{m}^{2}\right) \\
\text { Heartburn/reflux (\%) } \\
\text { Intolerance to Solids (\%) } \\
\text { Regurgitation (\%) }\end{array}\end{array}$ & $\begin{array}{c}32.8 \pm 5.8 \\
11 \\
6 \\
0\end{array}$ \\
\hline $\begin{array}{r}\text { Follow up at } 6 \text { months } \\
\text { BMI }\left(\mathrm{kg} / \mathrm{m}^{2}\right) \\
\text { Heartburn/reflux (\%) } \\
\text { Intolerance to Solids (\%) }\end{array}$ & $\begin{array}{c}29.8 \pm 3.3 \\
6 \\
6\end{array}$ \\
\hline $\begin{array}{r}\text { Follow up at } 12 \text { months } \\
\text { BMI }\left(\mathrm{kg} / \mathrm{m}^{2}\right) \\
\text { Heartburn/reflux (\%) } \\
\text { Intolerance to Solids (\%) }\end{array}$ & $\begin{array}{c}27.4 \pm 3.2 \\
6 \\
0\end{array}$ \\
\hline
\end{tabular}

sleeve gastrectomy secondary to dense adhesions. There were two staple-line leaks requiring reoperation (Table 2). There were no perioperative bleeds and no deaths. Symptom resolution was observed in $94 \%$ of patients at 1 year (Table 2). Postoperative BMI was $32.8 \pm$ $5.8,29.8 \pm 3.3,27.4 \pm 3.2$ at 3,6 and 12 months respectively. Average follow up time was 5.9 months.

\section{Discussion}

Gastric outlet obstruction is a significant complication following VBG, with outlet stenosis rates ranging between $10-20 \%$ of VBG patients $[3,7,8]$. While weights re-gain is the most common indication for revisional surgery, studies report over $30 \%$ of patients being revised from VBG in the literature were as a consequence of symptomatic outlet stenosis [3,12]. Almost half of our patients who had endoscopic evidence of gastric outlet obstruction were symptomatic. Vasas et al. found that approximately one-half of their revisional patients previously complained of intractable vomiting, one-third had reflux and one-quarter reported solid food dysphagia. Gastric outlet obstruction alsoresults in maladaptive high caloric eating behaviorsand often requires surgical correction $[3,15]$.

For gastric stenosis post-VBG, non-surgical modalities including endoscopic dilatation are often unsuccessful [3]. Poor response to initial endoscopic dilation is an important prognostic indicator for surgical management of outlet stenosis [16]. Surgical revision management options including conversion to the gastric bypass, VBG reversal and stoma revision have been described in the literature 
Citation: Switzer NJ, Gill RS, Shi X, Primomo JA, Morris L. Laparoscopic Revision of Vertical Banded Gastroplasty to Sleeve Gastrectomy for Gastric Outlet Obstruction: Early Experience in Cohort of 18 Patients. J Obes Bariatrics. 2016;3(1): 4.

[17]. Surgeons have shown consistent hesitancy to revisethe VBG to the LSG, as the belief was that a previously failed restrictive procedure is a relative contra-indication to a repeated restrictive procedure [18]. In addition, there exists a theoretical risk of increased leak rates from creating high intraluminal gastric pressures near a potential area of weakness at the site of the mesh or ring [3]. On the other hand, LSG is a relatively simpler procedure compared to the gastric bypass, and has the added advantages of being potentially a first step in a staged procedure for higher risk patients, avoiding the creation of bowel anastomoses, does not disrupt gastrointestinal continuity, and does not result in the nutritional deficiencies which plague the malabsorptive procedures [2,13]. Growing evidence also supports the notion that LSG is not merely a restrictive procedure, but through gut hormone modulation has an added weight independent effect mainly through the reduction of the hormone ghrelin levels through resection of the gastric fundus $[13,15,18,19]$.

Revisional bariatric procedures, in general, are associated with higher complications rate compared to the primary bariatric surgery $[2,20]$. Redo operations, in general, involve surgery in a scarred field with distorted anatomical planes [21]. In the case of conversion a band to LSG, dense fibrous tissue, adhesion formation from the original surgery, stapling through inflamed tissue at the band site, and potentially a compromised vascular supply of the new staple line have all been linked as factors attributable to this higher complication rate $[2,18]$.

Our results point to the efficacy and safety of conversion from VBG to LSG. This is one of the larger case series present in the literature of conversion to LSG from failed VBG $[2,12,13]$. The limited previous studies available in the literature support our findings. Berende et al. $(\mathrm{n}=23)$, Foletto et al. $(\mathrm{n}=5)$, Iannelli et al. $(\mathrm{n}=5)$ and Jacobs $(n=3)$ all converted VBG failure patients to LSG. These authors reported no perioperative mortalities, with staple line leak rates in VBG patients ranging from $8.6 \%$ to $40 \%[2,12,13,22]$. The authors felt that post-operative staple line leaks were the biggest challenge for these revisional VBG patients. Compared to the gold standard, RYGB, it appears that leak rates are higher in the LSG group [18]. In a systematic review comparing laparoscopic gastric banding revised to laparoscopic RYGB or LSG, staple line leak rates were $0.9 \%$ and $5.6 \%$ respectively, with the authors concluding that potentially after band removal the tissue of the stomach needs time to recover prior to being manipulated and stapled [14]. Almost all patients in our series achieved significant symptom relief from their gastric outlet obstruction with significant weight loss, with an acceptable staple link leak rate $(11.1 \%)$.

The purpose of our study was to show that the LSG is a safe option for revisional surgery for patients presenting with gastric outlet obstruction following a VBG. In our case series, there were no mortalities or major complications lending credence to the efficacy of LSG as a revisional option for failure of VBG as a result of gastric outlet obstruction.

This study is mainly limited by its small sample size. However, with almost universal improvement in symptoms following revision, lack of statistic power isn't as much of a concern. This study can be generalized to VBG patients specifically who suffer from outlet stenosis and symptoms of gastric outlet obstruction.

\section{Conclusion}

Vertical Banded Gastroplasty patients with symptomatic gastric outlet obstruction from outlet stenosis can be successfully and safely managed with conversion to Laparoscopic Sleeve Gastrectomy.

\section{References}

1. Jain-Spangler K, Portenier D, Torquati A, Sudan R (2013) Conversion of vertical banded gastroplasty to stand-alone sleeve gastrectomy or biliopancreatic diversion with duodenal switch. J Gastrointest Surg 17: 805808.

2. Berende CA, de Zoete JP, Smulders JF, Nienhuijs SW (2012) Laparoscopic sleeve gastrectomy feasible for bariatric revision surgery. Obes Surg 22: 330 334.

3. Vasas $P$, Dillemans B, Van Cauwenberge S, De Visschere M, Vercauteren C (2013) Short- and long-term outcomes of vertical banded gastroplasty converted to Roux-en-Y gastric bypass. Obes Surg 23: 241-248.

4. Lin YH, Lee WJ, Ser KH, Chen SC, Chen JC (2016) 15-year follow-up of vertical banded gastroplasty: comparison with other restrictive procedures. Surg Endosc 30: 489-494.

5. David MB, Abu-Gazala S, Sadot E, Wasserberg N, Kashtan H, et al. (2015) Laparoscopic conversion of failed vertical banded gastroplasty to Roux-en-Y gastric bypass or biliopancreatic diversion. Surg Obes Relat Dis 11: 10851091.

6. Abu-Gazala S, Sadot E, Maler I, Golomb I, Carmeli I, et al. (2015) Laparoscopic conversion of failed silastic ring vertical gastroplasty (SRVG) and vertical banded gastroplasty (VBG) into biliopancreatic diversion (BPD). J Gastrointest Surg 19: 625-630.

7. Suter M, Jayet C, Jayet A (2000) Vertical banded gastroplasty: longterm results comparing three different techniques. Obes Surg 10: 41-46; discussion 47

8. van Wezenbeek MR, Smulders JF, de Zoete JP, Luyer MD, van Montfort G et al. (2015) Long-term results of primary vertical banded gastroplasty. Obes Surg 25: 1425-1430.

9. Blero D, Eisendrath P, Vandermeeren A, Closset J, Mehdi A, et al. (2010) Endoscopic removal of dysfunctioning bands or rings after restrictive bariatric procedures. Gastrointest Endosc 71: 468-474.

10. Bradley JF 3rd, Ross SW, Christmas AB, Fischer PE, Sachdev G, et al. (2015) Complications of bariatric surgery: the acute care surgeon's experience. Am J Surg 210: 456-461.

11. de Gara CJ, Karmali S (2014) The anatomy of a weight recidivism and revision bariatric surgical clinic. Gastroenterol Res Pract 2014: 721095.

12. Foletto M, Prevedello L, Bernante P, Luca B, Vettor R, et al. (2010) Sleeve gastrectomy as revisional procedure for failed gastric banding or gastroplasty. Surg Obes Relat Dis 6: 146-151

13. lannelli A, Schneck AS, Ragot E, Liagre A, Anduze Y, et al. (2009) Laparoscopic sleeve gastrectomy as revisional procedure for failed gastric banding and vertical banded gastroplasty. Obes Surg 19: 1216-1220.

14. Coblijn UK, Verveld CJ, van Wagensveld BA, Lagarde SM (2013) Laparoscopic Roux-en-Y gastric bypass or laparoscopic sleeve gastrectomy as revisional procedure after adjustable gastric band--a systematic review. Obes Surg 23: 1899-1914.

15. Iannelli A, Amato D, Addeo P, Buratti MS, Damhan M, et al. (2008) Laparoscopic conversion of vertical banded gastroplasty (Mason MacLean) into Roux-en-Y gastric bypass. Obes Surg 18: 43-46

16. Holt PD, de Lange EE, Shaffer HA Jr (1995) Strictures after gastric surgery: treatment with fluoroscopically guided balloon dilatation. AJR Am J Roentgenol 164: 895-899.

17. Thoreson R, Cullen JJ (2008) Indications and results of reversal of vertical banded gastroplasty (VBG). J Gastrointest Surg 12: 2032-2036. 
Citation: Switzer NJ, Gill RS, Shi X, Primomo JA, Morris L. Laparoscopic Revision of Vertical Banded Gastroplasty to Sleeve Gastrectomy for Gastric Outlet Obstruction: Early Experience in Cohort of 18 Patients. J Obes Bariatrics. 2016;3(1): 4.

ISSN: $2377-9284$

18. Elazary R, Hazzan D, Appelbaum L, Rivkind Al, Keidar A (2009) Feasibility of sleeve gastrectomy as a revision operation for failed silastic ring vertical gastroplasty. Obes Surg 19: 645-649.

19. Bernante P, Foletto M, Busetto L, Pomerri F, Pesenti FF, et al. (2006) Feasibility of laparoscopic sleeve gastrectomy as a revision procedure for prior laparoscopic gastric banding. Obes Surg 16: 1327-1330.

20. Stefanidis D, Malireddy K, Kuwada T, Phillips R, Zoog E, et al. (2013)
Revisional bariatric surgery: perioperative morbidity is determined by type of procedure. Surg Endosc 27: 4504-4510.

21. Elnahas A, Graybiel K, Farrokhyar F, Gmora S, Anvari M, et al. (2013) Revisional surgery after failed laparoscopic adjustable gastric banding: a systematic review. Surg Endosc 27: 740-745.

22. Jacobs M, Gomez E, Romero R, Jorge I, Fogel R, et al. (2011) Failed restrictive surgery: is sleeve gastrectomy a good revisional procedure? Obes Surg 21: 157-160. 